\title{
What Is a Sexist Ideology? Or: Why Grace Didn't LeAve
}

\author{
HILKJE CHARLOTTE HÄNEL \\ Freie Universität Berlin
}

\begin{abstract}
This paper brings forward two claims. First, sexual violence is a social practice within a broader framework of sexist ideology. And, second, such an ideology is necessarily holistic and self-operative. I spell out the first claim with the help of Sally Haslanger's current research on social structures and ideologies. However, in order to show that a recent case of sexual violence is part of a broader sexist framework, I argue that we need to draw upon further research that focuses on the holistic and self-operative character of said ideologies. Additionally, I develop two insights that follow from understanding sexual violence as a social practice within a sexist ideology. If the sexist ideology constrains our actions and the intelligibility of our actions, then (a) the concept of consent becomes problematic in light of the sexist ideology, and (b) we should think about educational strategies to counter the sexist ideology, and not imprisonment.
\end{abstract}

$\mathrm{O}$ NE night in 2017, 'Grace' went on a date with actor Aziz Ansari. She later described the date as "the worst experience with a man I've ever had," and accused him of sexual assault (Harmon 2018; Respers France 2018; Way 2018). In a statement, he responded by saying that the sexual activity was completely consensual. While Grace felt pressured, uncomfortable, and violated, he was convinced that the sexual acts were consensual. How is it possible that a man who describes himself as an ally to the feminist cause engages in such unacceptable actions and seems incapable of understanding them for what they are, that is, acts of sexual violence ${ }^{1}$ And how is it possible that a woman who

1. In the following, I use the term 'sexual violence' to refer to sexual and sexualized acts that are either obtained through the means of power or for the end of power, e.g., acts such as rape, sexual assault, sexual abuse, sex obtained through psychological pressure, etc.

Contact: Hilkje Charlotte Hänel <hilkje.charlotte.haenel@fu-berlin.de> 
feels uncomfortable is still incapable of resisting further advances? In this paper, I argue that such cases have to be understood within the framework of a 'sexist ideology,' that is, a social structure that constrains our actions and epistemic tools of interpretation. What hinders Ansari from understanding the act as sexual violence and what hinders Grace from resisting Ansari is the complex set of interconnected sexist practices which determine who owes what to whom based on different gendered roles. ${ }^{2}$

In this paper, I make two claims. First, in light of the Ansari case, acts of sexual violence should be understood as social practices within a broader framework of sexist ideology. And second, such an ideology is necessarily holistic and self-operative. I spell out the first claim with the help of Haslanger's current research on social structures and ideologies. Ultimately, I argue that to make sense of the Ansari case as an example of sexual violence within a broader sexist framework, we need to draw upon research on the holistic and self-operative character of ideology. Roughly, I argue that a sexist ideology is holistic insofar as it is coherent and based on lived experiences, and self-operative insofar as it is constituted by interconnected social practices and takes on a "life of its own." I draw upon the work of Barbara Fields in my proposal for how to understand a holistic and self-operative ideology. According to my proposal, a sexist ideology is a social structure, constituted by ritualized social practices, and rationalized by a coherent cultural framework that organizes social agents into binary gender relations of domination and subordination. What I attempt to show is that the problematic and common experience of men who fail to correctly understand their own behavior as acts of sexual violence (e.g., Ansari) as well as the difficult phenomenon of women who are incapable of resisting an uncomfortable situation (e.g., 'Grace') can be better illuminated with a specific theory of ideology. Such a theory makes intelligible the ways in which those involved in certain social practices can fail to understand their own acts and experiences for what they are or fail to act according to their own best interests. ${ }^{3}$

Furthermore, locating the phenomenon of sexual violence within a broader

2. In this paper, I assume that Ansari does not understand his actions as acts of violence, but even if-as many have claimed-Ansari does understand what he is doing and decides to ignore the fact that Grace feels uncomfortable, we still face the question of why Grace is incapable of resisting the unwelcome advances and actively continues to engage with Ansari?

3. There are two distinct phenomena at play in sexist ideology (and other ideologies): willful ignorance and false consciousness. While cases of willful ignorance involve often powerful agents who willfully ignore the oppressive features of the social structure or the domination of less powerful agents, cases of false consciousness involve agents who fail to understand a situation for what it is due to dominant social practices and false schemas. It is important to explicate both phenomena if we want to understand the character of ideology correctly. However, in this paper, my focus lies exclusively on the second phenomenon. For relevant literature on the first, see Medina (2016), Pohlhaus (2012), Tuana \& Sullivan (2006; 2007). 
sexist ideology highlights two more insights: (1) The feminist focus on consent becomes problematic in light of the prevalence of powerful sexist ideology. And (2) since sexist ideology constrains our actions and renders opaque the intelligibility of our actions, the solution to cases of sexual violence should not be limited to incarceration; instead, as feminists, we should think about educational strategies to counter sexist ideology. I also provide a second reason for why feminists should distance themselves from embracing a politics of incarceration, one that has to do with the intersections between sexist ideology and racist ideology.

I will proceed as follows. First, I summarize the well-known Ansari case. This case brings to the surface the problem that violators sometimes fail to realize that they committed an act of sexual violence and that those violated are sometimes incapable of leaving the unwelcome situation despite the absence of physical force or threat (Section 1). Second, I make sense of this case by treating it as a social practice within a broader framework of sexist ideology, and I explain in detail the nature of sexist ideology (Section 2). I then briefly discuss the advantages of my account of sexist ideology, and I close by highlighting two normative consequences that my account brings forward: the inadequacy of the notion of consent and the failure of strategies of incarceration (Section 3).

\section{A Case of Sexual Violence}

One night in 2017, a woman known only by the pseudonym 'Grace' went on a date with actor Aziz Ansari. She later described the date as "the worst experience with a man I've ever had," and accused him of sexual assault (Harmon 2018; Respers France 2018; Way 2018). In a statement, he responded by saying that the sexual activity which took place between him and the woman was, "by all indications completely consensual" (Harmon 2018). While Grace felt pressured, uncomfortable, and violated by his behavior, he was convinced that the sexual acts were consensual. Even more so, he was convinced that they enjoyed a fun night together, as he texted her in a message the next day: "It was fun meeting you last night" (Way 2018). In this case, Ansari fails to understand his actions as acts of sexual violence. He seems unaware of the violation and the harm he inflicted.

According to Grace, Aziz Ansari ignored both verbal and non-verbal clues of discomfort, and he pressured her to engage in sexual acts. However, also according to her statement, Ansari did not ignore her verbal refusal; instead, he stopped the sexual interaction, and later asked again for further sexual conduct in the form of oral sex, to which she complied. What felt like compliance under pressure for her was a consensual sexual interaction for him. After he learned of her discomfort, Ansari released a statement saying that, "it was true that every- 
thing did seem okay to me, so when I heard that it was not the case for her, I was surprised and concerned" (Way 2018).

While some feminists have praised Grace for coming forward about this seemingly "normal" case of sexual behavior, a case that gained massive attention during the \#MeToo-movement, others have accused her of weakening this movement. In an opinion piece for the New York Times, Bari Weiss writes that, "if you are hanging out naked with a man, it's safe to assume he is going to try to have sex with you," and that, "if he pressures you to do something you don't want to do, use a four-letter word, stand up on your two legs and walk out his door" (Weiss 2018). Jessica Valenti, on the other hand, writes that,

a lot of men will read that post about Aziz Ansari and see an everyday, reasonable sexual interaction. But part of what women are saying right now is that what the culture considers 'normal' sexual encounters are not working for us, and [are] oftentimes harmful. (Respers France 2018)

Valenti is right in saying that often "normal" sexual encounters are harmful. And Weiss is correct in saying that Grace could have walked out-according to her statement, Ansari pressured her, but she stayed of her own free will. But the greater question is: Why did she not leave? Why did Grace feel unable to refuse the pressure and just leave when Ansari did not pick up on her clues of discomfort? And why did Ansari fail to pick up on these clues?

What I claim in the following is that Ansari's as well as Grace's behavior are constrained by a powerful sexist ideology, and that we fail to understand cases like this if we ignore the underlying sexist framework that structures them. In other words, I claim that Ansari's failure to adequately understand his actions and Grace's incapability of leaving the uncomfortable situation should be understood as social practices within a wider framework of - what I call-'sexist ideology'. Roughly, sexist ideology is constituted by sexist social practices that result from the interdependency of cultural schemas (a.k.a. social meanings) and resources. Sexist ideology constrains our actions as well as our epistemic tools for interpreting those actions. In the next section, I first explain how sexual violence is a specific social practice, and then develop an account of sexist ideology that can interpret acts of sexual violence as social practices within that ideology. 


\section{Sexual Violence, Social Practices, and Sexist Ideology}

In every presently existing society, human beings live under conditions of gender and sexual inequality. ${ }^{4}$ Not only is gender and sexual inequality a serious problem in developing countries, it is a persistent issue in highly developed countries such as the US and the UK. In the US, only slightly more than $20 \%$ of senior job positions are held by women. And both in the US and the UK, more than $20 \%$ of businesses have no women in senior management positions. For men and women in similar positions, men are paid significantly more for the same work as women. Furthermore, the vast majority of unpaid domestic work in the household is done by women. ${ }^{5}$ In the UK, significantly more women than men earn less than the living wage (Helm 2013). Single parent poverty overwhelmingly burdens women; $90 \%$ of single parents are women and $42 \%$ of single parents live in poverty (Bennett 2015). And one out of nine pregnant women or mothers on maternity leave quit their jobs for being treated poorly (Topping 2015). Finally, women in comparison to men suffer at significantly higher rates from domestic abuse and sexual violence: in the UK, one in five women experiences at least one sexual offence from the age of 16 , and one in twenty experiences rape, attempted rape, sexual assault, or attempted sexual assault. In the US, one out of every six women experiences an attempted or completed rape in her lifetime, with $14.8 \%$ completed and $2.8 \%$ attempted. ${ }^{6}$ Conviction rates are nevertheless very low; in the UK, only $15 \%$ of incidents are reported and $7 \%$ of the incidents reported to the police result in convictions. In the US, 994 perpetrators out of every 1000 rapes are not incarcerated.7 Transgender persons, individuals with sexual orientations other than heterosexuality, and individuals who do not conform to the binary gender system or dominant gender norms suffer similar high rates of sexual violence and are additionally targets of hate crimes. There were 1008 homophobic hate crimes and 50 transphobic crimes reported in 2012 and 2013 in London alone (Antjoule 2013). And, in the US, at least 27 transgender persons were killed in 2017. The social structure we live in-one determined by sexist ideology, as I will argue -is one which allows for and normalizes sexual violence, domestic abuse, forced marriage, homophobia, transphobia, forced

4. The aim of the paper is to explicate the features of an operative sexist ideology in the contemporary US and the UK. Nevertheless, I think that a benefit of the model of sexist ideology is that it is multiply realizable; that is, sexist ideology can be said to exist in various cultural contexts and societies, albeit realized in different forms and to different extents.

5. See the UN Human Development Report 2015: http://hdr.undp.org/en/content/humandevelopment-report-2015-work-human-development; accessed June 7, 2018. 2018.

6. See RAINN: https://www.rainn.org/statistics/victims-sexual-violence; accessed June 7 ,

7. The conviction rate for rape is significantly lower than for any other crime. See RAINN: https://www.rainn.org/statistics/criminal-justice-system; accessed June 7, 2018. 
surgery on intersexed persons, the gendered division of labor, male networks, glass ceilings, the gender pay gap, traditional and patriarchal family values, and so on. Ultimately, sexist ideology is about binary gender relations; roughly, men who conform to the ideals of masculinity have power over others, and those who challenge binary gender relations, and its subsequent norms, face sanctions. ${ }^{8}$ This is the background to the Ansari case discussed in the beginning.

Sexual violence is one piece of this social structure. Although sexual violence is composed of empirical acts, it is more than just that; it has a specific social meaning. I argue that sexual violence is a social practice only intelligible within a social structure that imposes a specific meaning onto such acts. To gain a more detailed understanding of sexual violence as a social practice and, ultimately, part of sexist ideology, I use a simplified version of Sally Haslanger's model of social structures and social practices. Social structures are constituted by sets of interconnected social practices that come into being through the interplay of resources and schemas. ${ }^{9}$ Schematically, we can present it like this:

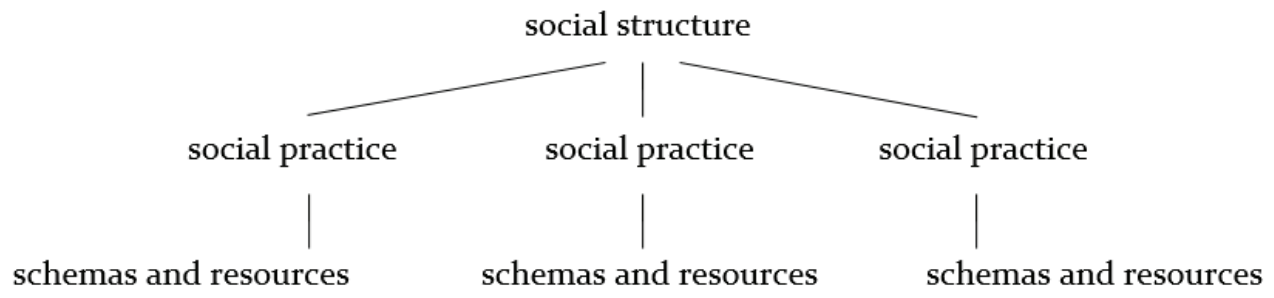

As one can see, the social structure is constituted by sets of interconnected social practices. And each social practice is constituted by interdependent schemas and resources. I now turn to the constituents of the model, starting with schemas and resources.

According to the Haslangerian account, schemas "are clusters of culturally shared mental states and processes, including concepts, attitudes, dispositions,

8. Often when we invoke the notion of sexist or patriarchal ideology what we have in mind is a specific system that structures the gender relations between men and women. Hence, one might ask why I here focus on men but do not mention women. The reason is simple. While I have in mind a structural system in which the social group of men (potentially) uses power over others, not merely women are subject to the use of that power (in the form of sexual violence, domestic abuse, etc.). Furthermore, the system that I have in mind is structured around binary gender norms and rules and as such affects especially those individuals who fall outside of the specific gender norms and rules. I come back to these issues later when I argue for a sexist instead of a patriarchal ideology.

9. According to Haslanger's original account, social structures are constituted by networks of social relations, which in turn are constituted by social practices. These practices come into being through the interplay of resources and schemas (Haslanger 2017). Here, I focus on social practices and thus use a simplified version of the Haslangerian model. 
and such, that enable us to interpret and organize information and coordinate action, thought, and affect" (Haslanger 2017: 21). In a similar vein, Quilter writes that "the 'schema' . . . structures how the 'reader' will 'interpret' the situation" (2011: 30). In contrast to concepts in the philosophy of mind or language, concepts are here meant in a psychological sense; they are a mechanism for storing default information (cf. Machery 2009). The schemas that we are interested in are cultural or public schemas; they enable us to act fluently in our everyday lives (Haslanger 2017: 21). In other words, schemas provide us with social meanings for everyday life. Resources, on the other hand, include everything that has value in any given sense. Resources with positive value are a source of power. The most basic examples of resources are material entities, such as money, food, housing, or books. However, things like knowledge, time, or physical skills can also be resources. The interdependence between schemas and resources is constitutive as well as causal. They are constitutively interdependent because without schemas we would be unable to make a specific resource intelligible as a resource, for example, we need schemas to think of an edible resource as foodafter all, not all edible things count as food (Haslanger 2017: 22). Schemas and resources are also causally interdependent since identifying something as a specific resource of food, for example, creates schemas that guide us through producing and cooking food. And these schemas can then affect how we think of certain resources. In other words, new schemas shed light on new resources and new resources can bring about a change in schemas. The interdependency of schemas and resources is a complex process that often proceeds without our (full) awareness (Haslanger 2017: 23).

Haslanger understands social practices to be constituted by interdependent schemas and resources, and thus emphasizes both their material and cultural components. Practices are not necessarily governed by rules and they need not be performed intentionally. Take the practice of driving; driving would not be possible without cars and certain other tools such as gas and streets, skills, and norms and rules. But we do not necessarily follow all the norms and rules consciously every time we drive a car. That is to say, social practices can be maintained without being cognitively transparent to us; often we unconsciously internalize social practices. The interdependency of schemas and resources can produce norms and social rules that guide our social practices explicitly as well as implicitly. I claim that sexual violence is a social practice. A simplified understanding of sexual violence takes it to be a resource in itself insofar as it can be used to enhance or maintain power (cf. Brownmiller 1975: 15). Yet, this explanation fails to capture the underlying dynamics of sexual violence. Part of the reason why sexual violence is used to enhance power is because of the specific social meanings attached to it. Sexual violence is thus better understood as a social practice constituted by interdependent schemas and resources. The re- 
sources at work in the Ansari case, for example, are Ansari's physical strength (even if he makes no use of it), the location of his apartment, his persistence, the distinct gender roles of Ansari and Grace, and so on. These resources stand in relation to schemas that make them intelligible; without certain schemas, his persistence would not count as a well-meant seduction technique and Grace would not think that she "owed" him. Distinct gender roles are, in a sense, made intelligible by schemas of who owes what to whom. According to Manne, for instance, women are givers and men are takers in the giver/taker dynamic that is part of gender roles (Manne 2018: 22). And, according to MacKinnon, women are per definitionem sexually submissive, while men are sexually dominant (MacKinnon 1987; 1989). Ansari and Grace thus have certain implicit expectations towards each other and towards themselves due to internalized schemas which provide them with distinct roles of giving and taking. Such schemas can make an act unintelligible as one of sexual violence-to both parties. Before I come back to this point, let me say more about the schemas at work in the social practice of sexual violence.

The schemas at work in the example above-and in most cases of sexual violence-are schemas that uphold binary gender relations in which men have power over others. This is made explicit by so-called rape myths. Rape myths legitimize sexual violence or make it appear as something that it is not, for example, seduction or "normal" sex (cf. Lonsway \& Fitzgerald 1994: 134). I propose that rape myths should be thought of as schemas which legitimize male entitlement to another person's body. Rape myths do this either by implying that the act in question was not an act of sexual violence, because it was implicitly wanted by the other person and was therefore consensual ("she asked for it"), or by making it into something else ("it wasn't really rape"). Rape myths as well as other schemas reflect societal attitudes that are widely and persistently held. Both Ansari and Grace are likely to be influenced by rape myths and schemas that bolster the binary gender system. ${ }^{10}$ This means that they were socialized into believing that men are entitled to another person's body in certain contexts. This helps us understand why Grace felt unable to refuse the unwanted advances and leave the apartment and why Ansari did not pick up on the verbal and non-verbal clues of discomfort. Remember that schemas and resources are constitutively and causally related. Without the rape myth schemas, certain resources would not exist as forms of power, for example, the schema that women are essentially givers renders a man's sexual persistence intelligible. Schemas thus affect how we think of certain resources. For example, knowing about the resource of an-

10. See Jenkins (2016) on how victims of rape and domestic abuse can fail to make intelligible their own experience because of false myths, and how that constitutes a form of hermeneutical injustice. 
other person's physical strength (even if it is not used) can elicit the schema of willful submission. Haslanger writes that reality "'pushes back' when we come to it with the wrong or an incomplete schema" (2012: 415). But reality does not push back in a case like the one above. Interpreting the resources as Ansari and Grace do is not only tolerated and accepted according to the norms of the social structure, it is the dominant interpretation. ${ }^{11}$

To summarize, the social practice of sexual violence is only intelligible within a social structure composed of determinate schemas and resources (including other social practices, e.g., very little institutional punishment for certain forms of sexual violence, etc.). And this is why some practices of sexual violence are not intelligible as acts of sexual violence. Let me take another example. Before recently, the practice of forced sex in marriage was inconceivable as an act of rape because the hermeneutical resources required to conceive of it as rape were lacking. The schemas needed to perceive marital rape as marital rape did not exist. The practice in question was still an act of rape, but it was masked by the existing hermeneutical schemas and resources. ${ }^{12}$ Furthermore, determinate social practices create a specifically sexist social structure which enables certain agents to sexually violate others (and get away with it) and for others to be sexually violated or to live in fear of being sexually violated. This social structure is reproduced through interconnected social practices that are constituted by interdependent schemas and resources.

How exactly does the social structure turn ideological? To answer this, I first need to explain two things: why does someone like Ansari, who is no stranger to feminism, engage in sexist practices without recognizing them for what they are, and why does someone like Grace, who feels violated, seem incapable of leaving the situation? Solving these puzzles becomes easier with the help of a specific theory of ideology. According to the theory of ideology which I will shortly lay out, the possible actions and self-understandings of social agents are constrained by the roles they occupy and norms that guide them. For example, men occupy a role that makes them believe they are entitled to the bodies of others and women occupy a role that makes them out to be sexual "givers". That is, women owe sexual gratification to men, and men are entitled to sexual gratification. Sexual violence is thus a result of the self-understanding accompanying the distinct roles that men and women occupy in the social structure. Women are

11. I come back to the false character of the dominant interpretations at the end of this section.

12. Compare Fricker's discussion of hermeneutical injustice, especially her example of sexual harassment (2007: 149-152). My account differs insofar as I concentrate on the social practices that are constituted by schemas and resources, while Fricker is interested only in the hermeneutical framework. Although Fricker's account raises interesting questions in regard to sexist ideology (e.g., is everyone within the ideology subject to hermeneutical injustice due to the absence or distortion of certain hermeneutical resources?), I do not have the space to discuss them here. 
constrained in their choice of resisting sexual pressure and men are constrained in their choice of how to interact with women sexually. When considering how to act in certain contexts, individuals are guided towards one choice or another by personal attitudes, habits, as well as the dispositions of those engaging with them. However, not every choice is available to them because they are set within a social structure in which they can only choose within their choice architecture. ${ }^{13}$ Sexist ideology, through its interconnected social practices, constrains the choice architecture according to its sexist norms and rules. And furthermore, the choice architecture is rationalized by the cultural framework, masking the ways in which we are constrained by ideology. ${ }^{14}$

In what follows, I argue that the specific social structure of which sexual violence is a part should be understood as a sexist ideology. ${ }^{15}$ This adequately captures the holism of the structure and the way it takes on a life of its own. It is only within such a sexist ideology that we can understand the particular problems of Ansari and Grace. ${ }^{16}$ According to Haslanger's theory, the social structure

13. One can think of the choice architecture as a map within which we make and act out our decisions; but not everyone with a sexist ideology has the same map, e.g., men have a broader map with more choices available (cf. Haslanger 2017).

14. Compare Young's (1990) account of injustice as constraining the choices of social agents.

15. There are important feminist and postmodern critiques levelled against the use of the concept of ideology as a tool for understanding oppression and power. Feminist criticisms often focus on the exclusion of women's oppression from ideology critique (cf. Keohane, Rosaldo, \& Gelpi 1982), and postmodern criticisms either focus on the problem that the judgement of a discourse from the perspective of another discourse is impossible (for a critique of this critique, see Larrain 1994) or they target the idea of representation which is taken to be implicit in any theory of ideology; the claim is that ideology does not misrepresent the world, because it does not represent the world at all. In regard to the task at hand-developing a theory of sexist ideology-the general feminist critique does not apply. Furthermore, the postmodern critiques of ideology theory rely on a picture according to which we, as social agents, represent our actions. This problematic assumption can be sidestepped by taking on board the idea that we do not represent our actions but "enact social structures simply out of habit formed through a process of socialization" (Haslanger 2017: 16). Hence, while postmodern critiques often focus on a hermeneutical account of ideology (or, in Foucault's words, 'discourse'), I contend that a deeper understanding of ideology can a) draw attention to the material and structural dimensions of social contexts, b) explain how social structures can develop beyond the self-interests not only of the oppressed but also the powerful (this is what I mean when I say that ideologies develop "a life of their own" below), and c) reveal the holism of the social structure.

16. Of course, the general idea of a sexist or patriarchal system is not new. Susan Brownmiller argues that men are structurally culpable of raping, while women are structurally vulnerable to being raped. Accordingly, rape is systematically used to keep all women in place (1975: 13-14, 17) Susan Griffin expresses a similar thought. She writes that women are never without the fear of being raped. According to Griffin, the sexual heteronormative system divides men into two categories: men who rape and men who protect women from being raped. This creates a protection racket against the "bad" men, in which women can get protection through chastity, virginity, or monogamy (Griffin 1971: 26). In a similar vein, Catharine MacKinnon argues that rape is a result of the institutionalized inequality between men and women. Social inequality between men and women defines every aspect of sexual behavior and, hence, makes acts of rape unintelligible 
consists of sets of interconnected social practices, which are constituted by interdependent schemas and resources. We can understand the social structure as the material and cultural framework in which the social activities of human beings take place at a specific place and time. As I have discussed, the social structure via its social practices consists of resources and cultural schemas. Cultural schemas have public standing; they are recognized and often internalized by social agents (although not necessarily endorsed) (Haslanger 2017: 23). In other words, cultural schemas allow "individuals to act fluently in social contexts" (Haslanger 2017: 21). According to Haslanger, a social structure is ideological if it

organizes us (a) in relations of domination and subordination (either through the production and distribution of goods, or in the constitution of selves), or (b) to resources whose value is misconceived or not recognized. (2017: 23)

Hence, an ideological social structure is one in which we value the wrong things or in which we are organized in unjust ways. ${ }^{17}$ In other words, a social structure can turn ideological either because of the specific relation between schemas and resources (i.e., between social meanings and particular objects) or because of the way that social practices organize the relations between agents.

However, Haslanger's account of ideology lacks an analysis of the holism and self-operativity of ideology, both of which are necessary for understanding the constrained interaction between Ansari and Grace. This is not to say that the Haslangerian model cannot account for these aspects, but rather that Haslanger has not explicitly spelled them out so far. Hence, I am making a friendly amendment to Haslanger's model that can be accommodated within its own terms. The conceptual framework of social structures as networks of interconnected social practices is apt to be understood holistically and, furthermore, the idea of the in-

as acts of rape (MacKinnon 1987: 82, 86-87). Rape is then the necessary outcome of a condition in which heterosexuality implies male dominance and female submission. The social position of women is thus to be "rapable" (MacKinnon 1989: 178). Finally, Claudia Card claims that rape is a historically specific terrorist institution, one in which the rules of rape become the second nature of its participants (1991: 297-299). What I add in the following is the explicit use of a theory of ideology to describe sexist social structures.

17. Again, I simplify Haslanger's complex theory of ideology. Haslanger uses the notion of cultural technē to explain the ideological character of social structures. According to her, a set of cultural schemas is a cultural technē and such a technē turns ideological if it is inherently unjust with regard to its power relations or its (material) resources. I speak of ideology instead of ideological technēs for reasons of simplicity. Furthermore, as I understand Haslanger's account, cultural technēs and ideologies are not the same, rather, cultural technēs turn into ideologies only when they become unjust. Finally, the notion of technē focuses on our hermeneutical frameworks (or, in Geuss' words, 'forms of consciousness' 1981: 13), however, according to Haslanger, ideologies concern hermeneutical frameworks interacting with (material) resources. 
terdependency between schemas and resources already suggests that ideologies can be self-operative. Let me now turn to Barbara Fields's account of ideology for an amendment. Similarly to Haslanger's account of ideology, Fields argues for an entanglement between social practices and cultural frameworks. Ideology provides a coherent interpretation of everyday life and its many social practices. In fact, Fields describes the social terrain that agents negotiate in a way congruent to Haslanger's use of cultural schemas. Fields argues that an ideology is not a set of beliefs that social agents decide to endorse, but rather that it is a negotiated social terrain "whose map they keep alive in their minds by the collective, ritual repetition of the activities they must carry out in order to negotiate the terrain" (Fields 1990: 113). Hence, similar to Haslanger's idea that social practices change along with changes in schemas and resources, the social terrain is also subject to negotiation. When the social terrain changes, individuals have to update their map. According to Fields, being able to change the social terrain means having power. Thus, both Haslanger and Fields endorse a similar set-up of ideological structures: real day-to-day experiences are ideological within a certain framework of interpretation that makes such experiences intelligible. ${ }^{18}$

How then does Fields account for the holism and self-operativity of ideology? According to Fields, ideologies are coherent insofar as they provide plausible maps for moving through everyday life to those who hold them. Ideologies make sense of our lived experiences and allow us to ritually and repetitively experience the same social practices over an extended period of time. It is through everyday rituals that ideology is re-created and verified. And the ritual character is twofold: it is based on the rationalization of social practices and the constant re-enactment of them, for example, we stop at a red traffic light because it is an advantage to do so and because of the constant re-enactment of that advantage.

18. Fields's account of ideology can be compared to current accounts of how social imaginaries function. (cf. Medina 2011; 2013; Fricker 2007; Gatens 2004; 2008). However, theories of social imaginaries tend to focus on the hermeneutical interpretation of social structures instead of the material resources and social practices that guide the accounts of Haslanger and Fields. Theorists of social imaginaries claim that the focus on truth and falsity in ideology theory is not what matters in regard to women's oppression. Instead, what matters is what generates meaning, and thus such theorists propose the concept of 'imaginaries', a concept that highlights the willful ignorance of oppression. (Yet, some also claim that the imaginary is in fact an important domain in which ideology might be at work, cf. James' interview with Gatens and Lloyd: James 1998) Although I think that an account of willful ignorance is essential for a complex investigation of oppression, what I am interested in here is the other side of the coin: the problematic phenomenon, first, that some social agents are not willfully ignorant but fail to understand their own behavior due to the dominant social structure, and, second, that individuals participate in the dominant social practices despite such practices being against their best interests. The questions we choose to investigate have consequences for the theoretical framework we take on board. Hence, my siding with accounts of ideology that focus on social practices instead of the hermeneutical framework is motivated by the very specific question I want to have answered. It should not be taken as a stance against other theoretical frameworks, which I believe are fruitful in regard to other questions. 
Ideology is therefore holistic in the sense that it is a coherent framework that governs our lived experiences over time and context. ${ }^{19}$ And it is self-operative insofar as the rituals and social practices we engage in over and over again change their meaning according to the overall framework without us being aware of it (Fields 1990: 110-111). However, according to Fields, ideologies are only potentially pejorative. That is, we could live within an ideological framework in which our everyday experiences and social practices are not necessarily based on false interpretations or are organized in unjust ways. As we have seen, Haslanger endorses a view according to which ideologies are necessarily pejorative (2017: 23). I therefore propose pairing Haslanger's and Fields' accounts:

An ideology is a social structure, constituted by ritualized social practices, governed and made intelligible by a coherent cultural framework that organizes us into relations of domination and subordination.

What then is a sexist ideology? A sexist ideology is a social structure, constituted by ritualized social practices, governed and made intelligible by a coherent cultural framework that organizes us into binary gender relations of domination and subordination. Social practices that constitute sexist ideology are sexual violence, domestic abuse, forced marriage, forced surgery of intersex persons, hate crime against transgender persons, and so on. To be coherent, the cultural framework functions with a range of schemas (including rape myths) that make intelligible the sexist social practices grounded in binary gender relations. Thus, when I speak of sexist ideology, I have in mind a whole range of interconnected social practices.

Recently, Kate Manne has brought forward an account of sexism as "the branch of patriarchal ideology that justifies and rationalizes a patriarchal social order" and "misogyny as the system that polices and enforces [patriarchy's] governing norms and expectations" (2018: 20). According to Manne, misogyny is one extreme tool of patriarchal ideology, and sexism is another. On my account, however, misogyny - as understood by Manne-can be seen as a tool of sexist ideology. Yet, I contend that there is at least one important argument for thinking of ideology as sexist and not patriarchal. I am not disputing Manne's overall account, just one part. Despite many feminist arguments for abandoning the concept of patriarchy, Manne does not give a strong reason for calling the ideol-

19. Note that the holism claim does not imply that we cannot criticize the ideology. This would be implausible considering that any social structure is fragmented and includes counterscripts, contested norms, and divergent practices. Instead, it implies that we are unlikely to break free of it from one moment to the next. Rather, overcoming an ideology is a historical process which has set-backs and is sanctioned by other agents within the ideology. 
ogy at work 'patriarchal'.$^{20}$ In its broadest sense, patriarchy describes a system in which men hold material, epistemic, and social power. Historically, this described the autocratic power of the father or husband-the head of the family. However, the social structure underwent a long development from a more classical patriarchal structure, in which women were directly controlled by the male head of the family, to the modern social form we have today. Taking stock of this shift is not to negate the historical significance of patriarchy or the many literally patriarchal ways in which the structure still functions today. When I invoke the notion of a sexist instead of a patriarchal social structure, I mean to make explicit the historical shift that occurred, a shift that has moved away from (but not beyond) problems concerning property relations and traditional family norms and towards problems of binary gender relations and heteronormativity. The notion of a sexist social structure highlights the ways in which the failure to conform to binary gender norms is sanctioned; it thus widens the focus beyond family structures. ${ }^{21}$ In the suggested account of sexist ideology, I take on board two insights: (1) Sexual violence is part of a holistic structure that gives it meaning and gives meaning to sexuality in general (the holism claim), and (2) the holistic structure takes on a life of its own insofar as it is constituted by interconnected social practices (the self-operative claim). While Manne focuses on the dichotomy of men versus women and argues for an agential and psychological picture of misogyny and sexism, I instead suggest an account of sexist ideology that takes seriously its holism and self-operative nature. This allows me to make sense of the changing character of the ideological structure of sexism and its transformation into a logic of binary gender norms.

Sexual violence as a social practice within sexist ideology is supported by other social practices and by the underlying cultural framework - the set of interdependent public schemas - that makes certain acts unintelligible or masks interpretations by providing alternative and false understandings. We can now understand how Ansari fails to understand his behavior as an act of violence and how Grace believes that she "owed" him. The sexist ideology they are embedded within masks a more adequate interpretation of their own experiences and instead provides a dominant but false alternative explanation. Rape myths are false or distorted, as are other sexist schemas that legitimize male entitlement to other persons' bodies, establishing a dichotomy of giving and taking. Without

20. For example, MacKinnon invokes the term 'male supremacy' (1989) instead of patriarchy, some sociologists refer to 'hegemonic masculinity' (cf. Connell 2005), others to 'male privilege' (cf. McIntosh 1988).

21. Note also that Manne does not draw a distinction between sexism and sexist ideology, in fact, she uses these notions interchangeably, suggesting a discursive framework of justification and rationalization of ideology - and not, as I have argued for, a model of ideology that focuses on social practices. She thus leaves open the possibility of an account of sexist ideology (in which both sexism and misogyny play a role). 
invoking the complicated discussion of true and false explanations and real and false interests in ideology theory, the general idea is that rape myths are in fact myths and not a depiction of reality. ${ }^{22}$ That is, the ideological social structure-in which rape myths are located-masks reality. There are two issues at play here: first, there is a conceptual problem of how the social structure masks reality, and, second, there is the ontological problem of the status of that which is masked. In other words, how does the social structure accommodate both true and false explanations? And, what makes rape myths (and other schemas) a myth rather than reality?

Let me tackle each of these questions in turn. First, according to Haslanger's model, three basic elements are relevant for the social structure: (material) resources, social meanings (e.g., sets of schemas), and structural constraints. The interdependency of resources and schemas enables specific social practices thatdepending on an agents' social position-pose constraints on their actions and choices. Hence, agents in a given social structure are informed by social meanings as well as material and structural conditions. This interplay of resources, schemas, and structural constraints can create so-called feedback loops; that is, the resources, the social meaning, and the constraints reinforce each other. Consider the following example: according to certain rape myths, women's passive submission implies consent to sexual interaction. Furthermore, because of the resources of superior physical strength and the knowledge that some men resort to violence when psychological pressure does not give them what they feel entitled to, it is a rational choice for most women not to resist unwelcome sexual advances for fear of escalating the violence. The passive submission that women exhibit in these situations strengthens the myth that women are in fact submissive and that submission implies consent. At the same time, avoiding violence by being submissive strengthens the narrative that submission is indeed the best choice to avoid violence. This feedback loop masks the fear of violence and the unwelcomeness of the encounter in a rape myth which can superficially claim that passive submission implies consent.

Second, how does the social structure accommodate true and false explanations? According to Geuss, an ideology - or an ideological social structureinvokes false beliefs via objectification mistakes or false interests (Geuss 1981: 13-14). Objectification mistakes are mistakes that take a social phenomenon as a natural phenomenon. This is the most obvious problem in regard to rape myths. Rape myths imply that the passive submission of women is in the nature of women, while it is in fact a response to the unequal social structure in which women exist at a particular historical moment. False interests, on the other hand, are interests that are real for some powerful subgroup but are presented as gen-

22. I come back to the problem of real and false interests in the last section of this paper. 
eral interests of all, for example, women's beauty norms. Feedback loops can also create interests and desires that are in no one's real interests or real desires; that is, because of the changing nature of social practices, we might be following some without knowing even why, or without them being beneficial to any of the participants. Hence, not all explanations are true and not all desires and interests are real within ideological social structures. To know what is and is not in our own interests, we need to engage in a process of critical reflection on the social structure itself.

One might argue that Ansari-as a (self-proclaimed) feminist ally-must know that the dominant views of men and women are ideologically sexist. That is, he must be in a position to question the ideologically distorted social practices. And, if that is the case, rather than saying that he failed to understand his actions for what they are, he chose to rely on alternative interpretations because they served him better. It is indeed realistic to assume that he knew about objections to the dominant view - after all, any social structure is fragmented and feminist views are not hard to come by in our time - and it is also realistic to assume that Grace has heard about counterarguments to the schemas of who owes what to whom. However, being aware of counterarguments is not necessarily sufficient to dislodge the coherent framework into which both Grace and Ansari were socialized. Ansari and Grace are both deeply entrenched in the ideology of sexism, that is to say, they unconsciously rely on ideological and thus false social meanings in their sexual interactions. Both of them re-enact ritualized practices within a coherent sexist framework. This is what makes sexist ideology so pervasive and hard to unmask.

This is precisely why many feminists criticize ideology theory. If ideology truly obscures reality, then how can some individuals ever come to see the truth (i.e., social reality as it really is)? And why do others remain trapped in 'false consciousness'? In other words, why does Grace correctly see Ansari's behavior as sexual violence while Ansari suffers from a false consciousness that restricts him from seeing his acts as such? While this question deserves more space than I can give it here, let me provide the following brief answer. While Grace, like Ansari, operates within the coherent sexist framework during the interaction, it is indeed the case that she comes to see the acts against her for what they are, while Ansari fails to do so. ${ }^{23}$ This is due to the fact that she is the one who suffers from

23. We could, at this point, circle back to the beginning of the paper where I discussed comments by Weiss and Valenti. Regarding these comments, we can now see how Weiss is beholden to sexist ideology and how her view is likely to be informed by rape myths. This can be seen in how she allows only a very narrow purview of what counts as genuine sexual violence and, hence, as worthy of public attention. Valenti, on the other hand, explicitly counters sexist ideology by explaining that some types of sexual violence-those that are too often assumed to be "normal" sexual behavior-are in fact acts of violation. That is to say, not all victims of sexual violence react by resisting or leaving the situation precisely because of their structural position and self- 
what is happening; she is the victim of a moral wrong. Often, when we experience situations of discomfort or violence, we have at least a vague feeling that something is going wrong even if the dominant interpretation tells a different story. That is, while we might not be able to adequately grasp what is going on, we are morally aware that what is happening is wrong. What we experience is a moral rupture; a moment of discomfort that reveals a gap between our own feeling of violation and the dominant cultural interpretation of what is happening to us. And it is this moral rupture that enables us to ask questions about the norms and rules of said culture and ultimately criticize the culture's overall ideological framework. ${ }^{24}$ Ansari fails to experience the moral rupture because of his social position. Elizabeth Anderson notes that social agents in structurally powerful positions "rarely have the characteristic experiences through which they would learn that what they are doing to social inferiors is wrong" (2014: 8). Ansari cannot learn from what happened in the same ways that Grace can because of their different social positions of power. While, in this particular case, Grace comes to see correctly while Ansari suffers from false consciousness, both parties could in principle suffer from false consciousness and both parties have the capacity to see correctly. This is important in addressing feminist criticisms of ideology theory, which often hinge on a worry about paternalism: false consciousness is then attributed to others that we want to criticize and never to oneself. This worry, however, rests on a mistake about the cognitive structure of ideology critique. In our case, we can say that Grace also suffers from a form of false consciousness that is deeply embedded in sexist social structures, which is evidenced by the fact that she did not leave, even though this option was open to her. Rather, she comes to see the acts against her for what they are because of an experience of moral rupture and the persisting narrative of sexist ideology. ${ }^{25}$

understanding according to the dominant sexist ideology. I am particularly grateful to one of the anonymous reviewers for this point.

24. I take it that this is also what Fricker and others have in mind in their accounts of hermeneutical injustice. While we might lack the hermeneutical resources to conceptually grasp the situation to its full extent, we nevertheless experience enough discomfort to seek help and formulate (better) concepts. (cf. Fricker 2007)

25. I am grateful to one of the anonymous reviewers for this point. I come back to the importance of this point in the last section when I discuss the importance of education over incarceration. There, it is crucial that Ansari has the potential to learn to see correctly, or experience a kind of moral rupture, even while being in a position of relative power. The process of critical reflection on social structures and practices that allows us to see correctly must in principle be available to alljust as we are all vulnerable to various forms of false consciousness in virtue of our participation in ideological social practices. If this were not the case, then strategies of public education would not be broadly effective. 


\section{Sexist Ideology, Consent, and Imprisonment}

While my analysis is useful in making sense of the problematic phenomenon of ideologically distorted experiences, some may wonder why the specific ideology theory I develop is better suited to the job than other theories. In other words, why this theory of ideology? The reason is because sexist ideology concerns not merely rape myths and other schemas, but also (material) resources and structural constraints; hence, it does not just concern the hermeneutical framework of our culture but also the specific social practices that we, as social agents, engage in. I take it that not only our attitudes and beliefs are factors in what choices we (can) make and which practices we enact, but also the material conditions, that is, there are material constraints in our physical world that produce and reproduce injustice (e.g., my movement depends on the availability of streets, transportation, etc.). Furthermore, material conditions can shape our hermeneutical frameworks and vice versa, and the feedback loops between these conditions and the frameworks mask the ideological structure. Hence, it is not sufficient to merely explicate the false consciousness (or social meanings in general) involved in ideology theory, we have to also see the interdependency of the hermeneutical framework with material resources and structural constraints. The theory of sexist ideology that I bring forward is guided by Haslanger's conception of materialist feminism; only an explication of epistemic as well as material conditions can explain how we engage in social practices that are against our best interests. (cf. Haslanger 2017: 25-26)

To illustrate what I have in mind, I will contrast my account with another theory of rape schemas. According to Quilter, legislative reform in rape law has little to no effect because of outdated legal requirements, such as the focus on resistance or the untrustworthiness of the complainant; these requirements form a schema which is applied to the specific case at hand. This schema brings it about that legislative reforms are "'unreadable' as they are circumvented and co-opted back into the 'old story"' (Quilter 2011: 31). Hence, the schema deems certain information-whether or not it has a basis in the actual legislative requirements - relevant while dismissing other information. With the help of Derrida, Bourdieu, and Butler, Quilter argues that the schema disciplines our understanding of 'true' rape despite the conflict between this understanding and the legislative reforms ${ }^{26}$ (Quilter 2011: 49-55). While Quilter's theory is useful for the circumscribed space of the court room, it lacks a fuller account of all the social conditions at play in sexist ideology, besides the hermeneutical frame-

26. Note the different use of 'schema' in Quilter's and my theory; while Quilter argues for one overall schema that represents the "true rape" - the narrative of what rape is -I argue that there are many diverse schemas in regard to sexual violence that together mold into a coherent social meaning. 
work. ${ }^{27}$ For example, Quilter's theory is apt to explain the false judgement of a jury according to the legal schema of rape, but it cannot accommodate the problematic structural constraints that influence Grace's choices and have her enact social practices not in her own interest.

As I argued in the last section, I contend that we need to take into account the interplay between material conditions, practices, and social meanings in order to understand the holistic and self-operative character of sexist ideology. After all, what we need to explain is how Ansari fails to understand what he is doing as sexual violence, on the one hand, and how Grace feels unable to leave the violent situation and remains trapped in the problematic dichotomy of who owes what to whom, on the other hand. Furthermore, acts of sexual violence are the most extreme part of a holistic system of inequality that shapes sexuality in general. In other words, my model of sexist ideology does not only make sense of the particular schema(s) of rape (as in Quilter's theory) but brings into focus the sexist structure of problematic binary gender relations. Hence, the particular theory of sexist ideology emphasizes (1) that sexual violence is part of a holistic sexist system that gives meaning to sexual violence as well as to sexuality and gender in general, and (2) that sexual violence is not the intentional power of all men over all women, but that the holistic system of which sexual violence is a part, transcends binary gender relations and has taken on a life of its own (beyond the control of individual agents within it). ${ }^{28}$ Finally, we cannot hope to change the ideological structure by merely changing our attitudes and beliefs. Instead, we have to tackle the hermeneutical frameworks and social meanings as well as the material conditions and overall social practices. Injustices are both epistemic and material.

My claim here is modest. I do not think that my account of sexist ideology in particular is better suited to explicate the complicated structures at work than some other theory of ideology. Rather, any ideology theory that focuses on social practices as constituted by schemas and (material) resources as well as the constraints imposed on social agents can bring about relevant insights. However, I contend that a fruitful theory has to include these specific components. The ideology model as stated above has the following advantages. The first is that it can account for how agents-both powerful and powerless-can (unwillingly) fail

27. Haslanger (2017) makes a similar point in regard to Butler's focus on discursive mechanisms.

28. By acknowledging that the social structure undergoes changes (from a patriarchal framework to a sexist framework, for instance), the social group in danger of sexual violence changes accordingly. A sexist social structure is not merely about women being (sexually) oppressed, for two reasons: (1) because of intersectional social relations (race, class, religion, age, bodies, etc. are important interlocking components in the analysis of sexist gender relations), and (2) because members of other social groups are affected in similar ways (e.g., transgender persons, persons who live outside the binary gender categories, persons who live outside the dominant gender norms). 
to understand their own experiences or enact problematic social practices. The second and third are negative, namely that such an account of sexist ideology reveals the shortcoming of overly focusing on consent and incarceration in discussions of sexual violence. These two insights follow directly from my account of sexist ideology, and are important for any feminist strategy against sexual violence. I turn to them now.

We have seen that sexist ideology constrains our actions and limits our ability to understand our own experience, and that this somewhat explains what went wrong in the example above. If this is the case, then (1) sexist ideology makes consent a more complicated matter; and (2) it suggests that incarceration is not an adequate reaction in many cases, but that rather we have to find ways to change the sexist structure. First, taking seriously the ways in which we are embedded in sexist ideology has implications for how we understand consent and whether it is a useful concept when it comes to understanding sexual violence. Take, for example, Lois Pineau's insightful discussion of when it is reasonable to assume that consent is indeed given. Pineau argues that, empirically speaking, women do not tend to enjoy the kind of sex that results from (psychological) pressure on a date. Since people usually do not consent to activities in which they have no interest, it is therefore unreasonable for a man on a date to assume (given the absence of active participation) that his date consents (Pineau 1989). This however assumes that we know what we want and we do not make choices against our best interest. However, such an assumption is questionable. After all, Grace did make a choice-she did not leave but engaged in pressured oral sex - that was against her best interest. Ideology can bring it about that women consent due to specific schemas, such as the one that makes it seem as though women owe sex to men; indeed, they might believe in the same schemas as men. Furthermore, growing up in a system that socializes women into being submissive (and enjoy it!) can render them incapable of distinguishing their real desires from their false desires. A woman might be so deeply influenced by the ideology that she actually believes that submission is her real desire. This is problematic for Pineau's theory and for how we understand consent, because it assumes that none of the participants in the sexual encounter are constrained by the choice architecture of sexist ideology and, hence, that they know what they want. Thus, in sexist ideology, consent-even enthusiastic consent-becomes questionable.

Second, as we have seen, sexist ideology constrains our actions and limits our ability to properly understand our own experiences. If this is the case, then we need to find ways to change the ideology. While the incarceration of perpetrators of sexual violence takes some individuals off the streets and protects other individuals from their actions, it is not always an adequate reaction to the ideological structure, as it does nothing to change said structure. Identifying sexual violence as a social practice within a sexist ideology suggests that we cannot 
tackle the practice by merely punishing individual perpetrators. Rather, we have to take into account the ideological structure that makes it possible for perpetrators to sexually violate in the first place. And, most importantly, we must work towards changing or abolishing this structure. Because the structure consists of social practices that are constituted by resources as well as social meaning, we have to work towards changing our practices and our means of interpretation. One way to do so is through relentless public education which tackles the false schemas that make our practices intelligible.

Finally, moving beyond incarceration is especially important due to the fact that sexist ideology is deeply entangled with racist ideologies. For example, the prevalent image of rape is often tinted with racist beliefs; in the US, this is the image of physically aggravated rape by a black stranger (or by a man from another minority group) (cf. Bar On 1999; Dines 1998). The US has a long history of using the image of the black rapist to legitimize lynchings and, later, convictions. Research shows that scenarios of date rape are more often judged to be acts of rape when the man involved is black and less often judged to be rape when the woman involved is black (Foley, Evancic, Karnik, King, \& Parks 1995). Hence, as long as sexist ideology is entangled with racist ideologies, we should at least be careful with strategies of incarceration in all cases of sexual violence and, instead, turn to educational and community based approaches of accountability and responsibility.

\section{Acknowledgments}

I want to thank Jacob Blumenfeld, Christine Bratu, Sally Haslanger, Rahel Jaeggi, Mari Mikkola, Tamara Jugov and the participants of the Workshop on Justice in Gender Relations at the FU Berlin, as well as two anonymous referees for fruitful discussion and helpful comments.

\section{References}

Anderson, Elizabeth (2014). Social Movements, Experiments in Living, and Moral Progress: Case Studies from Britain's Abolition of Slavery. Paper presented at the Kindley Lecture, University of Kansas.

Antjoule, Nick (2013). The Hate Crime Report: Homophobia, Biphobia and Transphobia in London. Galop.

Bar On, Bat-Ami (1999). The Scottsboro Case. In Keith Burgess-Jackson (Ed.), A Most Detestable Crime: New Philosophical Essays on Rape (200-210 ). Oxford University Press.

Bennett, Fran (2015). Poverty in the UK: The Need for a Gender Perspective. UK Women's Budget Group. 
Brownmiller, Susan (1975). Against Our Will: Men, Women and Rape. Fawcett Books.

Card, Claudia (1991). Rape as a Terrorist Institution. In Raymond G. Frey and Christopher W. Morris (Eds.), Violence, Terrorism, and Justice (296-319). Cambridge University Press. https://doi.org/10.1017/CBO9780511625039.013

Connell, Raewyn (2005). Masculinities. University of California Press.

Dines, Gail (1998). King Kong and the White Woman: Hustler Magazine and the Demonization of Black Masculinity. Violence Against Women, 4(3), 291-307. https://doi. org/10.1177/1077801298004003003

Fields, Barbara (1990). Slavery, Race and Ideology in the United States of America. New Left Review, 1(181), 95-118.

Foley, Linda, Christine Evancic, Karnik Karnik, Janet King, and Angela Parks (1995). Date Rape: Effects of Race of Assailant and Victim and Gender of Subjects on Perceptions. Journal of Black Psychology, 21(1), 6-18. https://doi.org/10.1177/00957984950211002

Fricker, Miranda (2007). Epistemic Injustice: Power and the Ethics of Knowing. Oxford University Press. https://doi.org/10.1093/acprof:0so/9780198237907.001.0001

Gatens, Moira (2004). Can Human Rights Accommodate Women's Rights? Towards an Embodied Account of Social Norms, Social Meaning, and Cultural Change. Contemporary Political Theory, 3, 275-299. https://doi.org/10.1057/palgrave.cpt.9300178

Gatens, Moira (2008). Conflicting Imaginaries in Australian Multiculturalism: Women's Rights, Group Rights, and Aboriginal Customary Law. In Geoffrey Brahm Levey (Ed.), Political Theory and Australian Multiculturalism (151-170). Berghahn Books.

Geuss, Raymond (1981). The Idea of a Critical Theory: Habermas \& the Frankfurt School. Cambridge University Press.

Griffin, Susan (1971). Rape: The All-American Crime. Ramparts, 10, 26-35.

Harmon, Steph (2018, January 15). Aziz Ansari Responds to Sexual Assault Allegation. The Guardian. Retrieved from https://www.theguardian.com

Haslanger, Sally (2017). Critical Theory and Practice. Koninklijke Van Gorcum BV.

Haslanger, Sally (2012). Resisting Reality: Social Construction and Social Critique. Oxford University Press. https://doi.org/10.1093/acprof:0so/9780199892631.001.0001

Helm, Toby (2013, November 2). More Than 5 Million People in the UK are Paid Less than the Living Wage. The Guardian. Retrieved from https://www.theguardian.com

James, Susan (1998). The Power of Spinoza: Feminist Conjunctions, Interview with Moira Gatens and Genevieve Lloyd. Women's Philosophy Review, 19, 6-28.

Jenkins, Katharine (2016). Rape Myths and Domestic Abuse Myths as Hermeneutical Injustices. Journal of Applied Philosophy, 33(4), 394-421.

Keohane, Nannerl, Michelle Rosaldo, and Barbara Gelpi (1982). Feminist Theory: A Critique of Ideology. University of Chicago Press.

Larrain, Jorge (1994). The Postmodern Critique of Ideology. The Sociological Review, 42(2), 289-314. https://doi.org/10.1111/j.1467-954X.1994.tbooo91.x

Lonsway, Kimberly A. and Louise F. Fitzgerald (1994). Rape Myths: In Review. Psychology of Women Quarterly, 18, 133-164. https://doi.org/10.1111/j.1471-6402.1994.tboo448.x

Machery, Edouard (2009). Doing Without Concepts. Oxford University Press. https://doi. org/10.1093/acprof:0so/9780195306880.001.0001

MacKinnon, Catharine (1987). Feminism Unmodified. Harvard University Press.

MacKinnon, Catharine (1989). Toward a Feminist Theory of the State. Harvard University Press.

Manne, Kate (2018). Down Girl: The Logic of Misogyny. Oxford University Press. https:// doi.org/10.5744/florida/9780813054391.003.0003 
McIntosh, Peggy (1988). White Privilege and Male Privilege: A Personal Account of Coming to See Correspondences Through Work in Women's Studies. Manuscript in preparation.

Medina, José (2011). The Relevance of Credibility Excess in a Proportional View of Epistemic Injustice: Differential Epistemic Authority and the Social Imaginary. Social Epistemology, 25(1), 15-35. https://doi.org/10.1080/02691728.2010.534568

Medina, José (2013). The Epistemology of Resistance: Gender and Racial Oppression, Epistemic Injustice, and Resistant Imaginings. Oxford University Press. https://doi.org/10.1093/ac prof:0so/9780199929023.001.0001

Medina, José (2016). On Refusing to Believe: Insensitivity and Self-Ignorance. In Astrid V. Wagner \& José M. Ariso (Eds.), Rationality Reconsidered (187-199). De Gruyter. https://doi.org/10.1515/9783110454413-013

Pineau, Lois (1989). Date Rape: A Feminist Analysis. Law and Philosophy, 8(2), 217-243. https://doi.org/10.1007/BFo0160012

Pohlhaus, Gaile (2012). Relational Knowing and Epistemic Injustice: Toward a Theory of Willful Hermeneutical Ignorance. Hypatia, 27(4), 715-734. https://doi.org/10.1111/ j.1527-2001.2011.01222.x

Quilter, Julia (2011). Re-Framing the Rape Trial: Insights from Critical Theory about the Limitations of Legislative Reform. Australian Feminist Law Journal, 35, 23-56. https:// doi.org/10.1080/13200968.2011.10854458

Respers France, Lisa (2018, January 17). Everyone Is Picking Sides over the Aziz Ansari Story. CNN. Retrieved from https://edition.cnn.com

Sullivan, Shannon and Nancy Tuana (Eds.). (2006). Feminist Epistemologies of Ignorance. Hypatia 21(3, Special Issue).

Sullivan, Shannon and Nancy Tuana (Eds.). (2007). Race and Epistemologies of Ignorance. SUNY Press.

Topping, Alexandra (2015, July 24). Maternity Leave Discrimination Means 54,00o Women Lose Their Jobs Each Year. The Guardian. Retrieved from https://www.theguardian.com

Way, Katie (2018). I Went on a Date with Aziz Ansari. It Turned into the Worst Night of My Life. Babe. Retrieved from https://babe.net

Weiss, Bari (2018, January 15). Aziz Ansari Is Guilty. Of Not Being a Mind Reader. The New York Times. Retrieved from https://www.nytimes.com

Young, Iris M. (1990). Justice and the Politics of Difference. Princeton University Press. 